\title{
GAMBARAN KARIES DENGAN KEBIASAAN MINUM SUSU BOTOL PADA ANAK BALITA
}

\author{
Cahyo Nugroho ${ }^{1}$ \\ ${ }^{1}$ Dental Therapy, Poltekkes Kemenkes Tasikmalaya, Jawa Barat, Indonesia \\ "cahyojkgtasik@gmail.com
}

\begin{tabular}{ll}
\hline Informasi artikel & ABSTRAK \\
\hline Sejarah artikel: & Tujuan penelitian ini untuk mengetahui Gambaran Karies \\
Diterima & Dengan Kebiasaan Minum Susu Botol Pada Anak Balita di Paud \\
Dipublikasikan & Raudhatus Salam Desa Kaliwulu Kecamatan Plered Kabupaten \\
\hline Kata kunci: & Cirebon. Jenis penelitian ini menggunakan metode penelitian \\
Karies, Susu Botol, Anak & deskriptif. Populasi nya seluruh murid di Paud Raudhatus Salam \\
Balita & Desa Kaliwulu Kecamatan Plered Kabupaten Cirebon. Teknik \\
& pengambilan sampel dengan kriteria total sampling yaitu sampel \\
& yang diambil adalah seluruh populasi dijadikan sampel yaitu \\
& sebanyak 38 orang. Penelitian ini menggunakan cara \\
& pengumpulan data dengan teknik wawancara dengan paduan \\
& daftar pertanyaan (Kuisioner) dan teknik observasi yaitu \\
& melakukan pemeriksaan secara langsung pada populasi yang \\
& dimaksud, sehingga data yang terkumpul terdiri dari data primer \\
& dan data sekunder. Penelitian ini diolah dan dianalisa dengan \\
& menggunakan distribusi frekuensi minum susu botol terhadap \\
& indeks def-t. Hasil penelitian menunjukan rata-rata indeks def- $t$ \\
& dari 38 anak Paud Raudhatus Salam adalah 3,68, yang \\
& berdasarkan kriteria menurut WHO adalah berada pada kategori \\
& status karies sedang yaitu 2,7-4,4. Hasil ini menunjukan ada \\
& kesenjangan dan gambaran pengalaman karies terhadap minum \\
& susu botol di Paud Raudhatus Salam Desa Kaliwulu Kecamatan \\
& Plered Kabupaten Cirebon adalah masih kategori sedang
\end{tabular}

Key word:

Caries, Bottled Milk, Toddler

\begin{abstract}
The purpose of this study was to determine the picture of caries with the habit of drinking milk bottles in toddlers in Paud Raudhatus Salam Desa Kaliwulu Kecamatan Plered Kabupaten Cirebon. This type of research uses descriptive research methods. The population is all students in Paud Raudhatus Salam Desa Kaliwulu Kecamatan Plered Kabupaten Cirebon. The sampling technique with total sampling criteria is that the sample taken is the entire population made as many as 38 people. This study uses data collection techniques by interviewing a combination of questionnaires (questionnaires) and observation techniques that are conducting direct examination of the population in question, so that the data collected consists of primary and secondary data. This study was processed and analyzed using the frequency distribution of bottled milk on the def-t index. The results showed the average def-t index of 38 children of Paud Raudhatus Salam
\end{abstract}


Desa Kaliwulu Kecamatan Plered Kabupaten Cirebon was 3.68, which according to WHO criteria was in the category of moderate caries status, 2.7-4.4. These results indicate there is a gap and caries experience experience of drinking bottled milk in Paud Raudhatus Salam Desa Kaliwulu Kecamatan Plered Kabupaten Cirebon is still in the medium category

\section{PENDAHULUAN}

Menurut undang-undang kesehatan tahun 2009 berbunyi pembangunan kesehatan bertujuan untuk meningkatkan kesadaran, kemauan dan kemampuan hidup sehat bagi setiap orang, agar terwujud derajat kesehatan masyarakat yang setinggi-tingginya, sebagai investasi bagi pembangunan sumber daya manusia yang produktif secara sosial dan ekonomi. Penyebab terjadinya gangguan kesehatan pada masyarakat akan menimbulkan kerugian ekonomi yang besar bagi negara (Depkes, R.I., 2009).

Penekanan kerugian negara yang diakibatkan karena gangguan kesehatan maka harus dilakukan penanggulangan dengan upaya peningkatan kesehatan pada umumnya dan kesehatan gigi pada khususnya, hal tersebut dinyatakan dalam undang-undang kesehatan 2009 bahwa setiap upaya peningkatan derajat kesehatan masyarakat juga berarti bagi investasi pembangunan negara (Depkes, R.I., 2009). Undang-undang nomor 23 tahun 1992 pasal 10 menyatakan bahwa untuk mewujudkan derajat kesehatan dengan pendekatan pemeliharaan, peningkatan kesehatan (promotif), pencegahan penyakit (preventif), penyembuhan (kuratif), dan pemulihan kesehatan (rehabilitatif) yang dilaksanakan secara menyeluruh, terpadu dan berkesinambungan (Depkes, R.I., 2000). Upaya pemeliharaan diri sebaiknya dilakukan sedini mungkin karena penyakit gigi dan mulut sangat rentan pada kelompok-kelompok tertentu (Herijulianti, dkk., 2001).

Menjaga kesehatan gigi dan mulut adalah sendi utama menjaga kesehatan secara umum, terutama kesehatan alat pencernaan. Kesehatan gigi dan mulut penting bagi kesehatan dan kesejahteraan tubuh secara umum, gigi merupakan salah satu bagian tubuh yang berfungsi untuk berbicara, pengunyahan, dam mempertahankan bentuk muka. Gangguan kesehatan berdampak pada kinerja seseorang, selain itu menjaga kesehatan gigi dan mulut agar terhindar dari penyakit gigi dan mulut (Ramadhan, 2010).

Penyakit gigi dan mulut merupakan sesuatu yang biasa dan merata secara luas, tidak terlepas dari usia dan jenis kelamin, ras dan bangsa akan merasakan penyakit gigi dan mulut (Srigupta, 2004). Penyakit gigi dan mulut yang umumnya banyak ditemukan pada masyarakat adalah penyakit periodontal dan karies gigi. Survei Kesehatan Rumah Tangga (SKRT) 2011 menginformasikan bahwa 90\% penduduk indonesia mengalami penyakit periodontal dan $60 \%$ penduduk indonesia menderita karies gigi aktif atau kerusakan gigi yang belum ditangani (Depkes, R.I., 2011). Menurut organisasi kesehatan dunia (WHO), karies gigi adalah sebagai suatu proses patologi pasca erupsi yang terlokalisasi dan disebabkan oleh faktor luar. Proses ini dimulai dengan kerusakan jaringan email yang menjadi lunak pada akhirnya menyebabkan terjadinya kavita (Machfoedz, 2008).

Masalah tingginya angka penyakit gigi dan mulut saat ini sangat berpengaruh oleh beberapa faktor, antara lain faktor perilaku masyarakat seperti cara pemeliharaan gigi dan mulut yang kurang, pengetahuan yang kurang dan pola makan yang tidak sehat. Pola makan yang tidak sehat seperti memakan makanan yang manis sebelum tidur dan pemberian susu botol pada balita sebelum tidur (Heryaman, 2007).

Pemberian susu atau cairan manis lainnya pada balita dengan menggunakan botol dalam jangka waktu yang panjang akan menyebabkan kerusakan gigi (Karies) yang secara 
luas dan berlangsung dengan cepat. Karies susu botol banyak terjadi pada anak-anak karena sering mengkonsumsi minuman yang mengandung gula, seperti susu, sari buah dan minuman manis lainnya yang diberikan kepada anak menjelang tidur. Gula yang terkandung dalam minuman diserap langsung oleh bakteri yang terdapat pada plak gigi yang diubah menjadi asam akan menimbulkan kebusukan atau kerusakan gigi, hal ini disebabkan aliran air ludah pada saat tidur sangat kuat (Heryaman, 2007).

Hasil survei yang dilakukan Suryawati, dkk (2009) prevalensi karies gigi pada balita 3-5 tahun di Indonesia pada tahun 2009 sudah mencapai 81,7\%. Prevalensi menurut kelompok usianya, usia 3 tahun $60 \%$, usia 4 tahun $85 \%$ dan usia 5 tahun $86,4 \%$, besarnya prevalensi karies disebabkan karena banyaknya orang tua yang tidak tahu pentingnya menjaga kesehatan gigi anak pada masa pertumbuhan. Maka pemeliharaan gigi sebaiknya dilakukan sejak dini sejak anak usia 1-3 tahun, karena pada usia ini adalah proses rentan terhadap karies (Herijulianti, dkk., 2001). Karies merupakan suatu penyakit jaringan keras gigi, yaitu email, dentin dan sementum, yang disebabkan oleh aktifitas suatu jasad renik dalam suatu karbohidrat yang dapat diragikan. Tandanya adalah adanya demineralisasi jaringan keras gigi yang kemudian diikuti oleh kerusakan bahan organiknya. Akibatnya, terjadi invasi bakteri dan kematian pulpa serta penyebaran infeksinya ke jaringan periapeks yang dapat menyebabkan nyeri (Kidd dan Bechal, 1991). Menurut organisasi kesehatan dunia (WHO), karies gigi dapat diartikan sebagai suatu proses patologis pasca erupsi yang terlokalisasi dan disebabkan oleh faktor luar. Proses ini dimulai dengan kerusakan jaringan email yang menjadi lunak pada akhirnya menyebabkan terjadinya kavita (Machfoedz, 2008).

Karies adalah suatu proses kronis regresif yang dimulai dengan larutnya mineral email sebagai akibat terganggunya keseimbangan antara email dan sekelilingnya yang disebabkan oleh pembentukan asam microbinal dari substrat sehingga timbul destruksi komponen-komponen organik yang akhirnya terjadi kavita, prosesnya terjadi terus berjalan ke bagian yang lebih dalam sehingga membentuk lubang yang tidak dapat diperbaiki kembali oleh tubuh melalui proses penyembuhan (Maulani, 2005). Karies hanya terjadi pada bagian gigi yang rentan terkena karies seperti pit dan fissure, besarnya seperti ujung jarum dan kedalamannya hanya mengenai lapisan email atau Iritasi Pulpa (Margareta, 2012).

Hasil survei yang dilakukan oleh Munawaroh (2009) di TKA/TPA Al-Ihsan Jalan Terusan Gagak Lumayung RT/RW 04/21 Desa Kota Wetan Kecamatan Garut, diperoleh data prevalensi karies sebesar 97,14\% dan decay, extraction, filling, teeth (def-t) rata-rata sebesar 10, 77 .

Hasil survei yang dilakukan oleh Komaswati (2007) di TPA R.A Darul Ihsan, diperoleh data prevalensi karies sebesar 96,9\% dan decay, extraction, filling, teeth (def- $t$ ) rata-rata sebesar 5,8 artinya masing-masing anak mempunyai pengalaman karies 6 gigi. Susu botol adalah susu sapi yang telah diproses oleh industri makanan atau susu menjadi produk yang sesuai untuk bayi atau balita. Susu ini biasanya berbentuk serbuk dan harus dicairkan sebelum diberikan kepada bayi (Beck, 2000, cit., Komaswati, 2007). Susu botol atau susu formula adalah susu komersil yang dijual di toko, biasanya terbuat dari susu sapi atau susu kedelai yang diperuntukan untuk bayi, dan komposisinya disesuaikan mendekati komposisi ASI dan diberikan didalam botol (Yayah dan Husaini, 1988). Susu botol adalah susu yang dibuat dari susu sapi atau susu buatan yang diubah komposisinya sehingga dapat diberikan sebagai pengganti ASI (Pudjiadi, 2002).

Karies susu botol adalah Karies yang ditemukan pada anak yang mempunyai kebiasaan minum melalui botol. Karies dimulai pada gigi anterior atas kemudian gigi posterior atas dan bawah, sedangkan gigi anterior bawah jarang terkena karena adanya saliva dan posisinya terlindung oleh lidah. Botol seringkali digunakan sebagai pacifier 
(dot), terutama pada anak yang sulit untuk tidur. Biasanya botol diberi susu ataupun cairan manis lainya. Kondisi seperti ini juga dapat ditemukan pada bayi yang diberi ASI secara berkepanjangan (Tinnanof dan Susan, 2008).

Karies susu botol berbeda dengan Karies rampan. Karies susu botol adalah suatu penyakit gigi balita yang ditandai dengan kerusakan pada hampir seluruh gigi, terutama pada gigi rahang depan atas bagian sisi permukaan halus menjalar ke insisal gigi. Karies rampan adalah Karies yang terlihat secara tiba-tiba, cepat meluas, melibatkan pulpa dan mengenai gigi geligi anterior rahang atas lalu menyebar ke seluruh permukaan gigi (Aris, 2009, cit, Munawaroh, 2010).

Indikator karies gigi dapat berupa prevalensi karies dan indeks karies. Indeks karies gigi yaitu angka yang menunjukan jumlah gigi karies seseorang atau sekelompok orang. Pengukuran karies dikenal sebagai indeks $D M F-T$ dan def-t yang merupakan indeks aritmatika penyebaran karies yang komulatif. Beberapa metode pengukuran karies gigi yaitu indeks $D M F-T$ digunakan gigi yang karies, hilang dan permukaan gigi yang ditambal pada gigi permanen, sehingga jumlah permukaan gigi yang terkena karies harus diperhitungkan. Indeks yang sama untuk gigi sulung adalah def-t digunakan untuk gigi yang karies, gigi yang hilang dan permukaan gigi yang ditambal pada gigi sulung (Kidd dan Bechal, 1991). Berdasarkan uraian dari latar belakang masalah tersebut maka tujuan penelitian ini untuk mengetahui Gambaran Karies Dengan Kebiasaan Minum Susu Botol Pada Anak Balita di Paud Raudhatus Salam Desa Kaliwulu Kecamatan Plered Kabupaten Cirebon

\section{METODE}

Jenis penelitian ini menggunakan metode penelitian deskriptif yaitu melihat gambaran atau keadaan pengalaman karies pada anak balita di Paud Raudhatus Salam Desa Kaliwulu Kecamatan Plered Kabupaten Cirebon Tahun 2015. Populasi pada penelitian ini adalah seluruh murid di Paud Raudhatus Salam Desa Kaliwulu Kecamatan Plered Kabupaten Cirebon Tahun 2015 sejumlah 38 murid. Teknik pengambilan sampel dengan kriteria total sampling yaitu sampel yang diambil adalah seluruh populasi dijadikan sampel. Penelitian ini menggunakan cara pengumpulan data dengan teknik wawancara dengan paduan daftar pertanyaan (Kuisioner) dan teknik observasi yaitu melakukan pemeriksaan secara langsung pada populasi yang dimaksud, sehingga data yang terkumpul terdiri dari data primer dan data sekunder. Penelitian ini diolah dan dianalisa dengan menggunakan distribusi frekuensi minum susu botol terhadap indeks def-t.

\section{HASIL DAN PEMBAHASAN}

Berdasrakan hasil penelitian mengenai karies pada anak balita yang meminum susu memakai botol anak dapat diperlihatkan pada Tabel berikut ini:

\section{Tabel. 1 Distribusi Frekuensi Pemberian Susu Botol Anak Balita Paud Raudhatus Salam Berdasarkan Jenis Kelamin}

\begin{tabular}{|c|c|c|c|c|c|c|c|c|c|c|c|c|}
\hline No & \multicolumn{8}{|c|}{ Frekuensi Minum Susu Botol } & \multirow{2}{*}{ Jumlah } & $\%$ \\
\hline 1 & $\begin{array}{c}\text { Tidak } \\
\text { pernah }\end{array}$ & $\%$ & Pernah & $\%$ & $\begin{array}{c}\text { Kadang- } \\
\text { kadang }\end{array}$ & $\%$ & Sering & $\%$ & $\begin{array}{c}\text { Sangat } \\
\text { sering }\end{array}$ & $\%$ & & \\
\hline 2 & $10 \mathrm{org}$ & 26 & $10 \mathrm{org}$ & 26 & 6 org & 16 & 6 org & 16 & 6 org & 16 & 38 org & 100 \\
\hline
\end{tabular}


Berdasarkan tabel 1 hasil penelitian ditemukan dari 38 anak Paud Raudhatus Salam, 10 anak yang tidak meminum susu botol (26\%), 10 anak yang pernah diberi susu botol (26\%), 6 anak yang kadang-kadang meminum susu botol (16\%), 6 anak yang sering meminum susu (16\%) dan 6 anak yang sangat sering meminum susu botol (16\%). Kemudian kejadian karies pada anak balita diperlihatkan melalui tabel berikut:

Tabel. 2 Distribusi Kejadian Karies Susu Botol Pada Anak Paud Raudhatus Salam Tahun 2015

\begin{tabular}{|c|c|c|c|c|c|c|c|c|c|c|c|c|}
\hline No & \multicolumn{9}{|c|}{ Pengalaman Karies } & \multirow{2}{*}{ Jumlah } & \multirow{2}{*}{$\%$} \\
\hline 1 & $\begin{array}{c}\text { Sangat } \\
\text { rendah }\end{array}$ & $\%$ & Rendah & $\%$ & Sedang & $\%$ & Tinggi & $\%$ & $\begin{array}{c}\text { Sangat } \\
\text { Tinggi }\end{array}$ & $\%$ & & \\
\hline 2 & 9 org & 24 & 7 org & 18 & 8 org & 21 & 6 org & 16 & 8 org & 21 & 38 org & 100 \\
\hline
\end{tabular}

Hasil pemeriksaan ditemukan dari 38 anak Paud Raudhatus Salam, 9 anak yang memiliki pengalaman karies sangat rendah (24\%), 7 anak yang pengalaman karies rendah (18\%), 8 anak yang memiliki pengalaman karies sedang (21\%), 6 anak yang memiliki pengalaman karies tinggi (16\%) dan 8 anak yang memiliki pengalaman karies sangat tinggi (21\%). Penelitian menunjukan dari 38 anak Paud Raudhatus Salam rata-rata indeks def- $t$ adalah 3,68, yang berdasarkan kriteria menurut $W H O$ telah ditetapkan kurang dari $3(<3)$, sedangkan hasil penelitian def- $t$ adalah lebih dari $3(>3)$, maka memiliki kesenjangan def- $t$ 0,68 . Hasil penelitian ini menggambarkan bahwa adanya kesenjangan dan karies dengan kebiasaan minum susu botol pada anak balita di Paud Raudhatus Salam Desa Kaliwulu Kecamatan Plered Kabupaten Cirebon, hal ini diperkuat oleh hasil penelitian yang dilakukan Winda, Gunawan, Wicaksono (2015) menunjukkan untuk 64 siswa dari PAUD di Desa Pineleng II Indah rata-rata indeks def-t yaitu 4,3. Frekuensi minum susu botol dengan tidak disertai rutin menggosok gigi bahkan berkumur setelahnya akan memicu timbulnya karies.

Minum susu menggunakan botol merupakan awal terjadi karies gigi pada permukaan gigi bila tidak dibersihkan dan merupakan tempat yang baik bagi kuman pembentuk asam sehingga dapat menimbulkan karies dan secara otomatis akan berpengaruh terhadap indeks def-t. Pendapat tersebut didukung oleh Nuraeni (2005) bahwa mengkonsumsi susu formula yang diberikan melalui botol adalah awal terjadinya karies gigi balita yang disebabkan oleh susu dari botol yang menempel pada gigi tidak dibersihkan, sehingga menimbulkan karies gigi.

Menurut Tinnanof dan Susan (2008) Pemberian susu botol pada anak balita merupakan penyebab kerusakan pada gigi anak balita karena susu yang diberikan melalui botol pada saat anak menjelang tidur sehingga dapat terjadi pengolahan asam susu yang menempel pada bawah lidah dan mulut sehingga dapat menurunkan derajat keasaman mulut yang dapat menyebabkan terjadinya rampan karies pada anak. Karies susu botol ini sering terjadi pada anak-anak karena sering mengkonsumsi minuman yang mengandung gula, seperti susu, sari buah, dan minuman ringan yang diberikan kepada anak menjelang tidur. Kontak yang berkepanjangan antara permukaan gigi dengan cairan yang mengandung gula akan menimbulkan pola yang khas dari gigi berlubang (Maulani, 2005).

Cara Pencegahan Karies Susu Botol adalah dengan Bila anak terbiasa minum susu dalam botol menjelang tidur dan sampai tertidur maka bersihkan giginya dengan menggunakan kain atau kasa yang telah dibasahi air hangat, meminum susu hanya dengan menggunakan gelas, apabila anak mengkonsumsi makanan dan minuman yang manis, sesudahnya diharuskan dibersihkan dengan cara kumur-kumur atau menyikat gigi (Sariningsih, 2012). 


\section{KESIMPULAN}

Hasil penelitian menunjukan rata-rata indeks def- $t$ dari 38 anak Paud Raudhatus Salam adalah 3,68, yang berdasarkan kriteria menurut $W H O$ adalah berada pada kategori status karies sedang yaitu 2,7-4,4. Hasil ini menunjukan ada kesenjangan dan gambaran pengalaman karies terhadap minum susu botol di Paud Raudhatus Salam Desa Kaliwulu Kecamatan Plered Kabupaten Cirebon adalah masih kategori sedang

\section{DAFTAR PUSTAKA}

Departemen Kesehatan, R.I., 1992, Bahan Bacaan Manajemen Laktasi, Direktorat Jendral Pelayanan Medik, Jakarta.

, 1995, Pedoman Pelayanan Kesehatan Gigi dan Mulut Ibu Hamil, Ibu Menyusui Balita, Anak Sekolah dan Puskesmas, Direktorat Jendral Pelayanan Medik, Jakarta.

, 2000, Pedoman Upaya Pelayanan Asuhan Kesehatan Gigi

dan Mulut Di Puskesmas, Direktorat Jendral Pelayanan Medik, Jakarta.

2009,Undang-Undang Tentang Kesehatan dan Kesehatan

Jiwa, Mahardika, Jakarta.

2010, Pedoman Pelaksanaan Stimulasi, Deteksi, dan Interpensi Dini Tumbuh Kembang Anak, Direktorat Jendral Pelayanan Medik, Jakarta.

Pelayanan Medik, Jakarta.

Herijulianti, E, Indriani, T.S, Artini, S., 2001, Pendidikan Kesehatan Gigi, Penerbit Buku Kedokteren EGC, Jakarta.

Heryaman, S, 2007., Pentingnya Kesehatan Gigi dan Mulut Anak, Kompas Jawa Barat, Bandung.

Kidd, A.M, Bechal, S.J., 1991, Dasar-Dasar Karies Penyakit dan Penanggulangan, Penerbit Buku Kedokteren EGC, Jakarta.

King, 1993., Usu Institutional Repositori, Http://Repositori.Usu.Ac.Id/Bitstream/, [13 Januari 2014].

Komaswati, E., 2007, Pengaruh Minum Susu Botol terhadap Terjadinya Rampan Karies Gigi Depan Rahang Atas Pada Anak Balita Di Tka/Tpa Al-Ikhsan Kecamatan Garut Kabupaten Garut Tahun 2007, KTI, Politeknik Kesehatan Gigi, Tasikmalaya.

Kurniasih., 2008, Konsep dan Pengertian Susu Formula, Http://www.babylonish.com/blog/2014/08/konsep-dan-pengertian-Susu-Formula/, [13 Januari 2014]. 
Machfoedz, I., 2008, Menjaga Kesehatan Gigi dan Mulut Anak-Anak dan Ibu Hamil, Fitramaya ,Yogyakarta.

Margareta, S., 2012, 101 Tips \& Terapi Alami Agar Gigi Putih dan Sehat, Yogyakarta.

Maulani, C., 2005, Kiat Merawat Gigi Anak, PT Gramedia, Jakarta.

Munawaroh, I., 2009, Hubungan Frekuensi Minum Susu Botol Dengan Indeks def-t Anak Prasekolah R.A Darul Ihsan Kecamatan Karang Pawitan Kabupaten Garut Tahun 2009, KTI, Politeknik Kesehatan Gigi, Tasikmalaya.

Nuraeni, L., 2005, Hubungan Konsumsi Susu Formula Yang Diberikan Melalui Botol Dengan Karies Gigi Anak Balita Diposyandu Madur Dan Balekambang Kecamatan Bojongasih Kabupaten Tasikmalaya Tahun 2005, Politeknik Kesehatan Gigi, Tasikmalaya.

Pudjiadi., 2002, Susu Formula, Https://creasoft,wordpress,com/susu-formula/, [13 Januari 2014].

Ramadhan, A.G., 2010, Serba Serbi Kesehatan Gigi \& Mulut, Penerbit Bukune, Jakarta.

Sariningsih, E., 2012, Merawat Gigi Anak Sejak Usia Dini, Kompas Gramedia, Jakarta.

Soebroto, I., 2009, Apa yang Tidak Dikatakan Dokter tentang Kesehatan Anda, Bookmark, Yogyakarta.

Srigupta, A.A., 2004, Panduan Singkat Perawatan Gigi dan Mulut, Prestasi Pustaka, Jakarta.

Sujiono, Y.N., 2009, Konsep-Konsep Dasar Pendidikan Anak Usia Dini, Http://Ebekunt.Wordpress.Co./2010/06/30/Konsep-Konsep-Dasar-Pendidikan-AnakUsia-Dini-3/, [13 Januari 2014].

Suryawati., 2009, Prevalensi Karies pada Balita, Http://Tantursyah.Blogspot.Com/, [13 Januari 2014].

Suwelo, I.S., 2000, Karies Gigi pada Anak dengan Berbagai Faktor Etilogi, Penerbit Buku Kedokteren EGC, Jakarta.

Sriyono, N.W., 2009, Pengantar Ilmu Kedokteran Gigi Pencegahan, Penerbit FKIK UGM, Yogyakarta.

Tinanoff, N, Susan, R., 2008, Update On Early Childhood Caries Since The Surgeon General's Report, Http://Ncbi.Nlm.Nih.Gov/Pmc/Articles/Pmc2791669, [13 Januari 2014].

Winda, S.U, Gunawan, P, Wicaksono, D.A., Gambaran Karies Rampan Pada Siswa Pendidikan Anak Usia Dini Di Desa Pineleng II Indah, Skripsi, DGFK Universitas Sam Ratulangi, Manado 2015. 
Home page: http://www.edukasional.com/index.php/ARSA

Yayah dan Husaini, 1988., Usu Institutional Repositori, Http://Repositori.Usu.Ac.Id/Bitstream/, [13 Januari 2014]. 